\title{
Phytoprotection
}

\section{Index des sujets, volume 81}

Subject Index, Volume 81

Volume 81, numéro 3, 2000

URI : https://id.erudit.org/iderudit/706209ar

DOI : https://doi.org/10.7202/706209ar

Aller au sommaire du numéro

Éditeur(s)

Société de protection des plantes du Québec (SPPQ)l

ISSN

0031-9511 (imprimé)

1710-1603 (numérique)

Découvrir la revue

Citer ce document

(2000). Index des sujets, volume 81 / Subject Index, Volume 81. Phytoprotection, 81(3), 135-136. https://doi.org/10.7202/706209ar d'utilisation que vous pouvez consulter en ligne.

https://apropos.erudit.org/fr/usagers/politique-dutilisation/ 


\section{Index des sujets, volume 81 Subject Index, Volume 81}

\section{A-B}

Acer saccharum

activité antimicrobienne

agriculture durable

agroécosystèmes / agroecosystems

Alternaria spp.

anoxia stress

antimicrobial activity

aphids

apple vascular breakdown

Ascochyta sp.

bark degradation

Beauveria bassiana

Bipolaris sorokiniana

Birds' nest fungi

Botrytis squamosa

Brassica

napus

rapa

brunissement vasculaire de la pomme

Bt-transgenic potato

Byssochlamys fulva

C-D

carrier zone formation

changements climatiques

Cladosporium spp.

climatic changes

contrôle microbien

contrôle naturel

Cronartium ribicola

Cyathus olla

Cyperus esculentus

cysts

décomposition du chaume

defence reactions

dégradation de l'écorce

désherbage

distribution spatiale

diversification / diversification

\section{$\mathbf{E}$}

écologie du paysage

élagage

émigration / emigration entreposage du grain

environmental factors

39

enzyme / enzyme 23

Epicoccum spp. $\quad 30$

Erwinia

carotovora ssp. atroseptica

carotovora ssp. carotovora

44

44

Eupenicillium

brefeldianum

32

lapidosum

32

\section{F-H}

15,35

40

facteurs environnementaux

39

forêt / forest

38

formation de barrière de protection

69

Fragaria ananassa $\quad 115$

frost hardiness $\quad 43$

Fusarium

moniliforme 97

oxysporum 97

sambucinum $\quad 37$

solani

solani forme A / form A

97

57

spp.

30,40

Gibberella zeae

33

23

38,42

grain storage

Gremmeniella

38,42

abietina

36

abietina european race

43,49

abietina race européenne

43,49

Heterodera glycines

57

\section{I-O}

Inonotus tomentosus 36

insolation hivernale $\quad 38$

kystes $\quad 57$

landscape ecology

Leptinotarsa decemlineata $\quad 15,107$

Lygus lineolaris

Malus pumila

35,115

matière opaque

30

69

37

15

33

1 
nutrient stress

opaque material

Ophiostoma

novo-ulmi

ulmi

organic and inorganic salts

P

Paecilomyces varioti

PCR-SSCP method

Phomopsis sp.

phosphine /phosphine

Phytophthora infestans

Picea

$$
\text { glauca }
$$

mariana

Pinus

banksiana

concorta

monticola

resinosa

strobus

pomme de terre transgénique-Bt

Populus deltoides $\times$ P. maximowiczii

Populus deltoides $\times P$. trichocarpa

pourriture des racines

productivité / productivity

pruning

pucerons

\section{R-T}

réactions de défense 40

Rhizoctonia solani

30

30

37,44

32

37

41

23

39,123

35,36

$35,36,43,49$

$36,43,49$

107

38

38

40, 97

31

32
43 root rot

40,97

sels organiques et inorganiques

37,44

Septoria musiva

38

Solanum tuberosum

44,123

spatial distribution

34

stress d'anoxie

stress nutritionnel

31

43

87

123

42

1

129

115

23

$35 \quad \mathbf{U}-\mathbf{Z}$

Ulmus americana

69

Vaccinium

angustifolium

myrtilloides

32,129

32

Venturia inaequalis

34,35

virus PVX

44

44

virus $\mathrm{PVY}$

115

volume rate

41

weeding

38

winter insolation

42

winter survival

43

41 